\title{
Que sabemos nós de nós mesmos?
}

Renata Pallottini

Poeta, dramaturga, contista, romancista, nasceu em São Paulo. Cursou Direito na Universidade de São Paulo (USP) e o Curso de Filosofia Pura na Pontifícia Universidade Católica (PUC/SP). Foi Diretora da Escola de Arte Dramática da USP, presidente da Comissão Estadual de Teatro da Secretaria de Estado da Cultura e Chefe do Departamento de Teatro da ECA/USP. Roteirizou o programa infantil Vila Sésamo e, nas décadas de 1970 e 1980, trabalhou como tradutora e roteirista de telenovelas e séries para a TV, entre as quais Malu Mulher (TV Globo).

Ministrou aulas na Itália (Embaixada do Brasil), na Universidad Autônoma de Barcelona (Espanha), em centros culturais de Lima e Cuzco (Peru) e na Escuela Internacional de Cine y Television de Havana (Cuba). Recebeu prêmios de Teatro - em 1965, o Governador do Estado e o Molière, e, em 1969, o Anchieta - e de Poesia: o Jabuti, em 1996, e o Cecília Meireles, em 1997, entre outros.

Entre suas últimas obras publicadas estão: Obra Poética (Editora Hucitec, 1995), o romance Ofícios e Amargura (Scipione, 1998), o ensaio Dramaturgia de Televisão (Moderna, 1998) e a peşa Colônia Cecília (Palaura Livre, 2002).

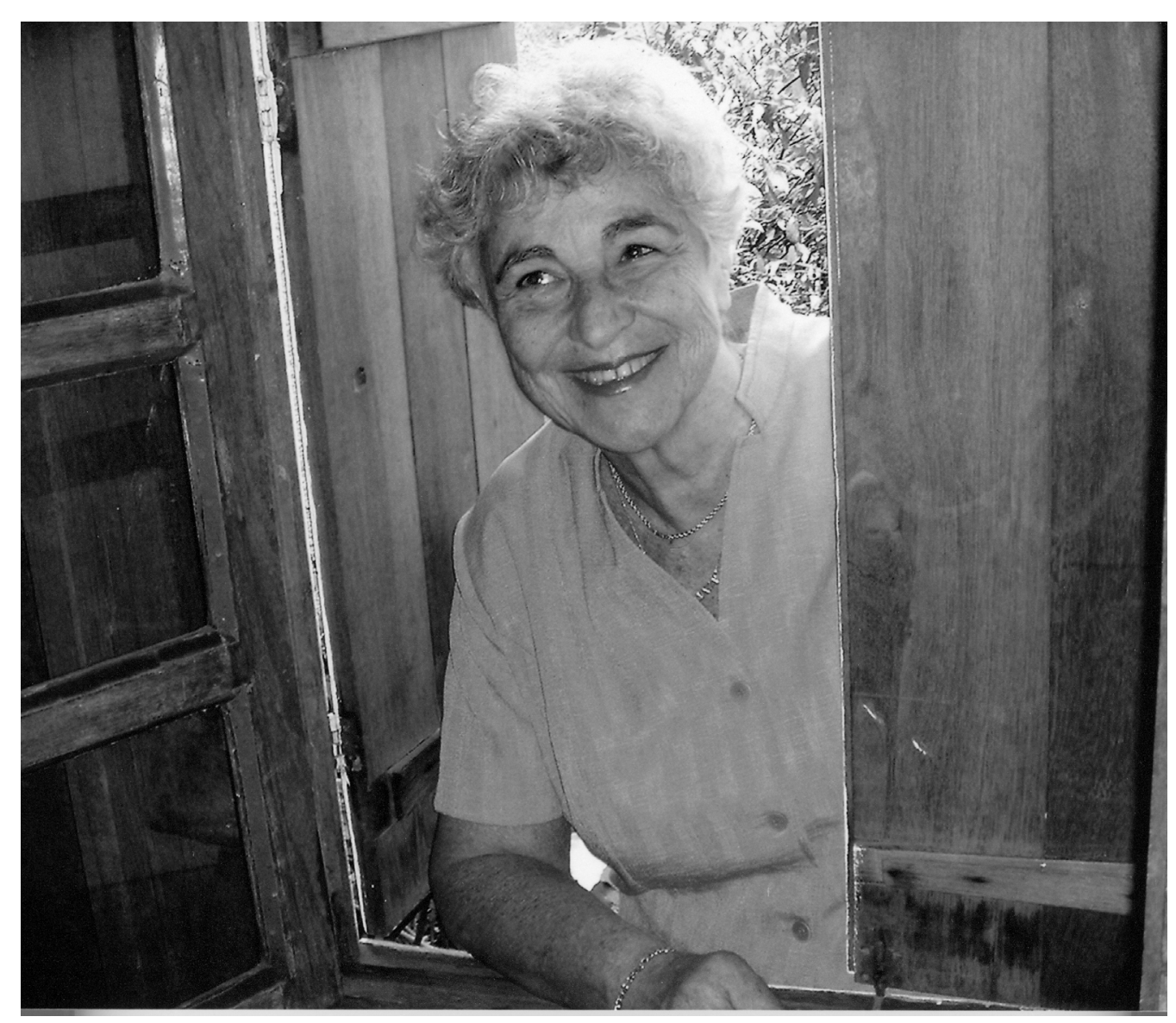


Por volta de 1970, estava eu, com outros companheiros de então, como professora do Departamento de Teatro da Escola de Comunicações e Artes da USP, encarregada do setor de Dramaturgia - além de ser professora de Literatura Dramática e Teatro Brasileiro na Escola de Arte Dramática, a EAD, anexada à ECA/USP. Funcionávamos num pequeno barracão, o B5, dividindo o espaço segundo o horário: o Departamento funcionava até as 5 horas da tarde e, depois, era todo da EAD. O barracão, que ainda existe - creio -, ficava do lado de lá, ou seja, do lado oposto ao que é, hoje, o prédio principal.

$\mathrm{Eu}$ tinha freqüentado aulas na antiga Escola de Arte Dramática particular, de propriedade e direção de Alfredo Mesquita, durante os anos de 1961 e 1962 (Curso de Dramaturgia e Crítica), estendendo um pouco o curso por minha vontade, para não perder o contato com mestres importantes, como Anatol Rosenfeld, Augusto Boal, Décio de Almeida Prado, Sábato Magaldi e Alberto D'Aversa.

Em 1964, por indicação do Sábato, Alfredo me convidou para entrar para o corpo docente, com o encargo de ministrar o curso de Teatro Brasileiro. Isso acontecia na velha Escola da Avenida Tiradentes, onde hoje está a Pinacoteca.

Lá fiquei até 1968, quando passamos todos para a responsabilidade da USP. Pouco depois, fui convidada a fazer parte do grupo de professores da ECA, lecionando Dramaturgia.

A essa altura, já tinha publicado três ou quatro livros de poesia e escrito algumas peças de teatro e textos para a televisão. Entre as peças estava O Crime da Cabra, comédia que me rendeu os prêmios Molière e Governador do Estado. Já havia ido, inclusive, a Paris, em 1966, no gozo do prêmio da Air France. Tinha sido uma boa estréia profissional, precedida por alguns textos curtos e seguida por outros, como Pedro Pedreiro, que a ECA levou ao festival de Manizales, na Colômbia, em 1969, com direção de Silney Siqueira; A História do Juiz, comédia várias vezes encenada; João Guimarães, Veredas, que Teresa Aguiar dirigiu para a Cia. Nydia Licia; e O Escorpião de Numancia, texto pelo qual ganhei o prêmio Anchieta.

Foi nesse momento que meu amigo e companheiro de trabalho Miroel Silveira, a quem eu mostrava tudo o que escrevia e a quem pedia freqüentemente orientação, me deu um inestimável conselho: "Quando é que você vai escrever um texto sobre você mesma? Quando é que você vai se colocar num texto?".

Todos sabemos que um autor sempre se coloca num texto. Em cada um dos personagens e na ação que eles desenvolvem, estamos sempre nós mesmos. Seria inútil pedir a um autor que fosse sempre totalmente objetivo e distanciado. Nem Brecht fez isso.

Mas há formas e formas de se colocar. O que Miroel me pedia era que eu falasse sem pudor de mim mesma, deixando de lado o medo e o constrangimento da confissão, embora soubesse, como eu sabia, que na reescrita de nós mesmos, quando a fazemos com o intento primordial do estético, ocorrem modificações profundas. Sem que nos dediquemos, nesse instante, a perguntar: que sabemos nós de nós mesmos?

Nesse dia, no dia da minha conversa com Miroel, nasceu a idéia de escrever Enquanto se vai morrer...

Comecei em 1971 e levei mais ou menos um ano para pôr no papel uma peça épico-lírico-dramática em que, sem preocupações com cronologia ou lugares de ação, com a maior liberdade, eu ia colocando em cena minhas experiências 
na Faculdade de Direito do Largo de São Francisco, onde vivera, estudara e amara entre os anos de 1949 e 1953.

Faziam parte do rol de personagens o Marquês de Beccaria (autor do clássico Dos Delitos e das Penas ${ }^{1}$, escrito em 1764 - extraordinário libelo contra a tortura, os julgamentos secretos e a pena de morte), o professor alemão Julius Frank que, por ser muito querido pelos seus alunos e tendo sido fundador de uma célula da maçonaria na Faculdade, a Bucha, acabou por ser lá enterrado, estando seu túmulo até hoje no pequeno pátio do andar térreo; e outros mestres, colegas, funcionários, poetas vivos e mortos, personagens imaginários que penetravam o tempo.

A peça, hoje eu sei, é uma apaixonada defesa do direito de amar e uma igualmente apaixonada acusação à pena de morte e ao castigo da tortura. Ainda gosto dela, mais de trinta anos depois, e ainda a considero um bom texto teatral.

Quando achei que a peça estava pronta, corri a submetê-la à crítica do Miroel, que se entusiasmou com a idéia (fazia restrição, apenas, à palavra morrer do título, que ele evitava sempre), tanto que imediatamente a recomendou para a montagem de fim de ano da ECA, com elenco dos finalistas do Departamento e direção de Celso Nunes, então professor.

Tudo pronto, o entusiasmo correndo solto e os preparativos iniciados, mandamos a peça para a Censura Federal, procedimento então obrigatório - ano de 1972 - para liberação e montagem.

Mas o ano era 1972 e o presidente-ditador-militar de então era Emílio Garrastazu Médici.

\section{CONCERTO DE CONDENAÇÕES}

Naqueles anos infaustos, a Censura Federal não costumava responder aos pedidos de exame quando a liberação era negativa. Simplesmente se omitia, com certeza supondo que os consulentes, experimentados e sem alternativas, depois de algum tempo desistiriam do pedido.

Mas nós insistimos na busca de resultados; e foi assim que, por intermédio do meu amigo Carlos Pinto, conseguimos receber, através de mediação do deputado federal Athiê Jorge Coury, em 1973, o seguinte telegrama:

Deputado Athiê Jorge Coury

Câmara dos Deputados

\section{NESTA}

Informo Vossência foram negados pedidos de liberação

para Enquanto se vai morrer et Cadela Humana

visto contrariarem legislação em vigor PT Rogerio Nunes, Diretor DCDP.

Assim, às secas. Comunicado por pressão de um deputado, obtido por mediação de um amigo. Postos lado a lado o texto de uma escritora que já tinha um currículo na literatura nacional e um título, ao que tudo indica, recusado por motivos ligados à moral (?) de então.
1. BECCARIA, Cesare. Dos Delitos e das Penas. São Paulo: Martin Claret 2002. (A obra-prima de cada autor). 
comunicação \& educação • Ano XII • Número 2 • maio/ago 2007

Nunca pude saber mais a respeito das razões reais, das alegações, dos motivos encontrados para a proibição da peça. Até que, no fim do ano de 2006, encontrei na ECA, durante um seminário, uma nova amiga, Miliandre Garcia, que se dispôs a me fornecer os documentos referentes ao fato. $\mathrm{E}$ assim o fez.

Recebi, então, os textos oriundos da Censura Federal.

Por me parecer que retratam uma época e porque foram decisivos na evolução da minha carreira como escritora de teatro, reproduzo aqui alguns trechos desses documentos.

O primeiro deles, por ordem cronológica, data de 9 de maio de 1973 e é assinado por Myrtes Nabuco de Oliveira Pontes, Hellé Prudente Carvalhedo e Roberto Antonio Coutinho.

Quem serão essas pessoas? Não sei.

No item Classificação Etária, já aparece a conclusão:

Pela não-liberação. Decreto n. 20. 493, art. 41, letras "d", "g" e "h".
Item Linguagem: subversiva.
Item Tema: de protesto.
Personagens: revoltados, insatisfeitos e revolucionários.
Enredo: reminiscências e experiências estudantis, dentro de um contexto to-
talmente crítico e subversivo.
Relatório final:
Partindo de lembranças passadas, bacharéis em Direito, no exílio,
descrevem fatos relacionados com suas experiências estudantis, de-
tendo-se em particular sobre críticas políticas, alusivas ao regime da
época, apresentando conotações com o atual: desprestigiando vultos
históricos (Getúlio Vargas); ridicularizando a imagem do militar;
inserindo sutilmente mensagens e conceitos contra o regime vigente;
focalizando de forma velada os conflitos e greves estudantis e os re-
sultados da interferência policial - estudante morto por metralhadora
e transformado em herói.
Considerando que o objetivo é de incitamento e revolta, dirigido frontalmente
à classe universitária, para a qual se destina a encenação da peça, julgamos
a mesma passível de interdição.

Quem seriam as pessoas que firmaram esse documento? Jovens? Universitários? Intelectuais? Mistério. De qualquer modo, funcionários públicos deveriam ser pessoas que exaravam pareceres, os quais definiam o futuro e a existência de um trabalho artístico, melhor ou pior, bem ou malsucedido. E, se malsucedido, em boa parte pela sua cautelosa defesa do statu quo.

Os outros pareceres seguem a mesma linha:

"[...] espetáculo apresentando a ridicularização do militar e críticas contra o regime vigente" (Carlos Alberto Braz de Souza). Ou: "A peça é inconveniente, considerando o momento político atual, tendo em vista o seu conteúdo de contestação, o seu caráter de protesto alusivo aos regimes políticos brasileiros, partindo da revolução constitucionalista de 32, passando por Getúlio Vargas e chegando à época presente" (Wilson de Queiroz Garcia). 
Como se vê, são demonizados a contestação, pura e simples, a crítica, o protesto, a revolução de 32, enquanto se canoniza, sabe Deus por quê, a figura de Getúlio Vargas.

Uma única voz se ergueu, nesse concerto de condenação: uma pessoa que me é desconhecida como as demais - Onofre Ribeiro da Silva. É seu o texto que se segue:

Como a tônica maior da peça gira em torno de memórias de ex-estudantes de Direito de uma mesma faculdade, relembrando velhos e atuais anseios, ainda que entre em méritos políticos de apreciações, a sua mensagem maior é positiva. Sim, porque todo o seu desenrolar envolve os estudantes em várias fases de sua vida. Nos pontos onde aparecem apreciações políticas dúbias, sugerimos os cortes assinalados. Porém, no cômputo geral, somos favoráveis à sua liberação, com restrição para públicos menores de 18 anos.

Como terá sido, depois, a carreira do Onofre na Censura Federal? Terá sido malvisto, marcado, discriminado? Terá posto acima de tudo, de sua carreira, de seu emprego, de seu salário, a opinião que livremente expressou?

O certo, para mim, é que a peça Enquanto se vai morrer... ficou escondida na gaveta, inédita, até a década de 1980. Nessa fase da vida nacional, já um pouco mais distendida essa passagem, pudemos fazer algumas leituras públicas, ou semipúblicas, uma delas no teatro Ruth Escobar, com boa platéia.

Mas (e o sabem muito bem os meus colegas de trabalho) não há compensação que satisfaça um autor impedido de levar à cena uma peça. A prova maior e mais crucial do valor de um trabalho dramático é o palco. É ver experimentado o seu diálogo, a capacidade e a potencialidade da sua palavra, feita para ser dita e não lida simplesmente (embora nada nos impeça de fruir um texto dramático numa simples leitura). É que se possa testar a comunicabilidade, a reação de público, o calor da convivência humana que há num teatro.

Desse modo ficou minha peça, até o dia em que Zécarlos de Andrade, um antigo aluno da Escola, que havia ficado, ele próprio, traumatizado pela proibição, resolveu levar à cena o meu texto, lá no lugar onde eu sempre tinha sonhado encená-lo: a própria Faculdade de Direito.

Assim se fez, em 2002, resgatando o meu desejo legítimo; mas é obvio que os trinta anos de silêncio obsequioso me tinham feito mal. A única coisa boa que a interdição produziu em mim foi a gestação de outro texto, Serenata Cantada aos Companheiros que, em 1976, sob a direção de meu companheiro de docência e amigo, Fausto Fuser, se montou no teatro Ruth Escobar. Dessa ocasião ainda me restam lembranças de um carro ocupado por quatro homens, que me abordaram, em seguida ao espetáculo, no meu próprio carro, perto da minha casa, que era então na Rua Tamandaré, fazendo-me advertências ameaçadoras sobre o fato de que minha peça fazia crítica aos estudantes de Direito, sob uma ótica comunista. Era ainda a continuação do espírito vigente nos anos 1970, que tantos males nos causou e tantas feridas incuráveis proporcionou.

Serenata não tinha nada de subversiva, nem mesmo do ponto de vista da Censura Federal, a qual, aliás, a liberou. Ela narrava - em 1976 - o reencontro de estudantes, depois de dez anos de sua formatura em Direito, seus desencantos, seus erros e acertos, sua felicidade e infelicidade. Fazia menção a colegas que estavam longe, distantes - no exílio -, e distinguia os resistentes dos acomodados. Embora a temática não fosse nova - o tema do reencontro tem sido muitas 
vezes utilizado -, era uma forma de fazer reviver, longe da tesoura censória, alguns personagens pelos quais eu tinha especial carinho.

Foi bom encenar essa peça, foi bom ver alguns colegas na platéia, simplesmente acenando ou simplesmente baixando a cabeça. Foi uma catarse.

Mas hoje, quando o fantasma da Censura, qualquer que seja o seu novo apelido, se nos apresenta outra vez, precisamos estar alertas. Não é de censura que precisamos.

É de liberdade, honestidade, decência, recursos para a educação, respeito à lei, revista e renovada sempre que isso seja necessário e, principalmente, cumprida sempre que seja justa.

Neste ano de 2007, no dia 22 de março, foi feita a reestréia, em Curitiba, no Paraná, de minha peça Colônia Cecília, em que se narra a história da colônia de anarquistas fundada nos campos próximos à cidade de Palmeira, no fim do século XIX, por Giovanni Rossi e seus companheiros. A montagem foi do Grupo Máscaras, no Teatro Guaíra, sob direção de João Luiz Fiani e com elenco de jovens profissionais do Paraná. A mesma peça já havia recebido na sua estréia, com direção de Ademar Guerra, os prêmios Gralha Azul de melhor espetáculo e melhor música original; e Lala Schneider, atriz paranaense recentemente falecida, recebeu o troféu de melhor atriz e Emilio Pitta, o de melhor ator, no Festival de 1984. Outras duas peças minhas estão em montagem².

Que os deuses nos ajudem a difundir o espírito dionisíaco e a medida apolínea que o teatro nos oferece.

São Paulo, 2 de março de 2007.

Resumo: Neste depoimento Renata Pallottini, poeta, dramaturga, contista, romancista, roteirista de telenovelas e séries para a TV ganhadora dos mais importantes prêmios, como o Governador do Estado, Molière, Jabuti e Cecília Meireles, entre outros, narra como se interessou por teatro e sua ida para a Escola de Arte Dramática da ECAUSP, nos anos 1970. Nesse período da vida política do Brasil, teve início um verdadeiro concerto de condenações às suas peças, começando por Enquanto se vai morrer..., uma apaixonada defesa do direito de amar e uma igualmente apaixonada acusação à pena de morte e ao castigo da tortura. Ficou trinta anos engavetada, até sair do silêncio em 2002. Por retratarem uma época e por serem decisivos na evolução da sua carreira como escritora de teatro, reproduz neste seu depoimento alguns trechos dos textos da Censura Federal aos quais teve acesso recentemente. Lembra-nos de que hoje, quando o fantasma da censura, qualquer que seja o seu novo apelido, se nos apresenta outra vez, precisamos estar alertas.

Palavras-chave: comunicação, teatro, censura, Escola de Arte Dramática - EAD ditadura militar.
Abstract: In her testimony Renata Pallottini, poet, dramaturge, writer of short stories, novels and Brazilian telenovelas and television series, awarded with the most import prizes as Governador do Estado, Molière, Jabuti and Cecília Meireles, among others, tells us how she was initially interested in theater and how she went to the Escola de Arte Dramática of ECA-USP, in the 70's. At that time in Brazilian political History, it began a concert of condemnations to her theater plays, what began with the play Enquanto se vai morrer..., a passionate defense of the right of loving and, equally, an accusation to capital punishment and to torture. It was kept from the audiences for 30 years, till it was taken from silence in 2002. Because they portrayed a time and because of their decisive role in her career as theater plays writer, she reproduces in her testimony some chunks of the Federal Censorship evaluations to which she recently had access. She reminds us that nowadays, when the ghost of censorship, whatever is its new nickname, is coming up again, we must be in state of alert.

Keywords: communication, theater, censorship, Escola de Arte Dramática - EAD, military dictatorship. 